\title{
Optimization and Simulation Approach for Empty Containers Handling
}

\author{
Chafik Razouk / PhD Student at ENSIAS \\ Cedoc ST2I - Operations Research \& Logistics \\ UM5S - Université de Rabat \\ Rabat, Morocco
}

\author{
Youssef Benadada \\ Smart Systems Laboratory, Rabat IT Center \\ ENSIAS, Mohammed V University in Rabat \\ Madinat Al Irfane, BP 713, Agdal Rabat, MOROCCO
}

\begin{abstract}
Container handling problems at the container terminals are NP-hard problems. In this paper, we propose a new handling operation's design and simulation of empty containers, taking into account the interrelated activities at the container terminal. This simulation have been built using a doubled trailer. It moves containers from quayside to yard side or the opposite depending on the flow in container terminal, and it is used to optimize the cycle time and to improve the efficiency of the other equipment. Our interest is to test this new model first for empty containers. The proposed model is applied on a real case study data of the container terminal at Tanger Med port. This new design was developed using Arena software and verifying the strength of materials constraint for the loaded containers. The computational results show the effectiveness of the proposed model, where the cycle time of the port equipment have been reduced by $\mathbf{- 5 8 \%}$, and the efficiency has been increased where $+47 \%$ of the moves in container terminal was achieved.
\end{abstract}

Keywords-Container terminal; design; doubled trailer; simulation; arena; strength of materials; quay

\section{INTRODUCTION}

Port container terminals are an important and crucial link between several intermodal transport modes. The important increase of containers volume handled at the container terminal (CT) was the root cause of the diversification of technologies and equipment used to facilitate the internal transition inside the CT. The majority of the ports are adapted to this new mode of transport by creating dedicated terminals in charge of loading and unloading container vessels as well as the storage and transfer of containers to trains or external trucks. Thus, the competition between container terminals become more and more important, and the CT authorities are obliged to improve the quality of their services to meet the needs and targets of their customers. The major concern of a CT is to provide more container handling capacity and improve the efficiency of its equipment.

A CT is a temporary storage space, where vessels berth in port terminal to unload inbound containers during the import operations and pick up outbound containers during the export operations, otherwise move containers from one vessel to another in case of transshipment. The concept of using containers has been standardized worldwide, an ISO standardized metal box is used to transport goods between continent, the most famous ones are: TEU, 40feet and 45feet (TEU: 20 feet equivalent units). They can be stacked then on top of each other following a 'last-in, first-out' (LIFO) strategy. Once the containers are transferred from the seaside to the yard side via internal vehicles, the yard crane will store them in a specific location based on certain criteria: destination, estimated departure time, weight and size. The below Fig. 1, shows the complete process and the equipment used in CT: quay cranes to unload inbound and pick up outbound containers, internal trucks to transfer containers between quay side and yard side, yard cranes to store and drop containers from the yard blocks, and finally external truck (XT) for customer delivery (gate) Razouk, Benadada and Boukachour (2016) [1].

Inbound containers are unloaded from the vessel using the last in first out strategy (LIFO), then some containers can be stored in the yard blocks at the bottom of the stack, in order to search them some unproductive movement are needed. The containers received in inbound process may contain goods or can be empty, which is our focus on this paper. Due to lack of accurate information, containers can be stacked in the wrong order. This reduces the productivity of the cranes and creates additional tasks (reshuffles) with no added value. Therefore, the transfer and the handling of containers become the first bottleneck in the port operations process. According to Stahlbok and Voss (2008) [3], the existing activities in a container terminal can take place in two main areas: the quayside and the yard side. Several literature researches are dealing with quayside, see below Fig. 2.

There are three main decision levels in container terminal problems: 1) Strategic decisions are long-term decisions that include the structure of the terminal, handling equipment and handling procedures. 2) Tactical decisions are medium-term decisions that are interested in determining the number of quay cranes, yard cranes, straddles, etc. 3) Operational decisions are short-term decisions and include the process to be followed by the quay cranes, the yard cranes, straddles, etc.

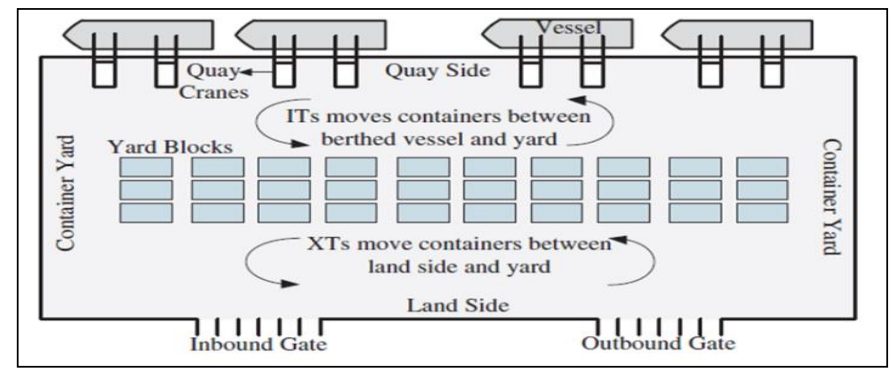

Fig. 1. Main area of container terminal [2]. 


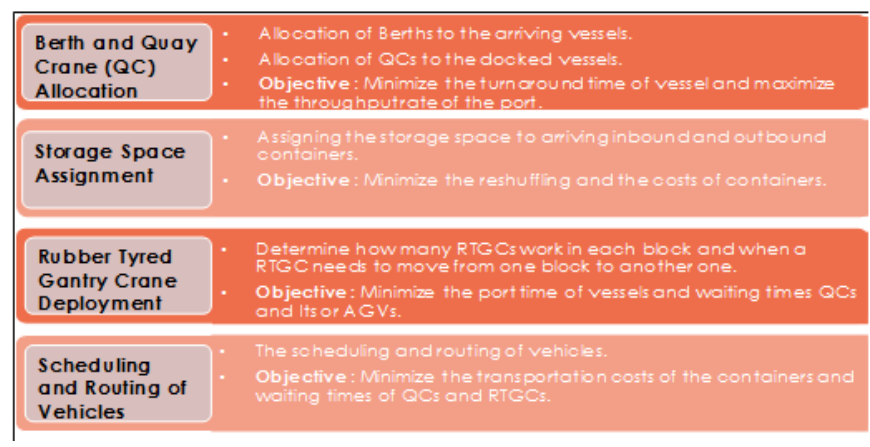

Fig. 2. Decision problems in container terminal [4].

As the port of our study is already built, and the equipment already known, we will try to focus in this paper on the operational operations. Our main objective is to optimize the related cost: minimize the cycle time of quay cranes (QC), improve the efficiency of the internal trucks and the empty handler $(\mathrm{EH})$ equipment and increase the number of moves per hour. For inbound and outbound empty containers, we study the impact of the current single trailer on the cycle time of the other equipment such as QC and EH. Then we measure and simulate the new cycle time result of using doubled trailer to transfer empty containers, the other type of containers will be treated in future works. The impact of our new model is well seen, where we optimizes the operation time by $54 \%$ and increase the number of moves by $48 \%$.

\section{LITERATURE REVIEW}

In this paper, we focus on the assignment of empty containers to the allocated space in the yard, the transfer between the quay and the yard side simulated with doubled trailer, and we measure later the impact on the cycle time and the efficiency of the other equipment used. Each yard area has a specific level to store empty containers; the stored empty containers on the last tier of the stacks must leave earlier to avoid unproductive movements (reshuffles, housekeeping). Thus, the objective is to place the received empty containers in an increasing order according to their departure time and their destinations Razouk, Benadada and Boukachour (2016) [5], and to reduce the number of the reshuffles by eliminating the housekeeping in the yard blocks (moves $\sim 0$ ) and to improve the efficiency and cycle time of the port equipment.

\section{A. Assignment of Group of Containers}

The main idea of the related research is to propose methods to assign groups of containers to storage locations, based on the vessel destination, departure time, and type of containers. A Simulated Annealing based heuristic for this problem is proposed by Huang and Ren (2011) [6] that require enumerating all possible assignment permutations for the three container groups of import containers, result is not compared with existing storage policies and didn't include the simulation approach. Jeong et al. (2012) [7] define a method to decide how many import containers will be stored in each block, the consigned strategy take into account only the destination of containers characteristics are not considered (e.g. case of empty containers). Nishimura et al. (2009) [8] propose a new MIP, and they use a new heuristic to minimize the weighted total container handling time. No additional constraint for the destination type or the type of the stored containers is considered. Razouk, Benadada and Boukachour (2015) [9] proposes a new formulation of the yard optimization problem and they used the consignment approach to assign containers, they used simple trailer but they did not treat the empty containers management. Therefore, our aim is to define specific formulation for empty containers and to use the consignment approach to assign them to the allocated space in the yard.

\section{B. Optimization and Simulation of the Yard Blocks}

Said and El-Horbaty (2015) [10] presents an approach using discrete-event simulation modeling to optimize solution for storage space allocation problem they didn't present any specific case for the empty containers nor include the different container characteristics they focused their work on the various interrelated container terminal handling activities. Kotachi et al. (2013) [11] presents a generic discrete-event simulation that models port operations with different resource types including rubber tyred gantry cranes (RTG), quay cranes, trucks, arriving and departing ships they didn't include in their simulation approach the type of trailer used nor the container characteristics.

A container yard used as a buffer for transshipment, discharging and loading containers, and is divided into blocks and bays. The yard optimization problem (YOP) defines the assignment of storage area (sub-blocks) to import and export containers at the containers terminal, the aim of YOP is to obtain a better space utilization of the yard, maximizing the throughput of the terminal and minimizing vessels handling time.

Several methods have been applied to solve the YOP separately without taking into account the different containers terminal activities. In our paper, we use the result of the resolution method of our mathematical model (optimization) as an input of our simulation model. Thus we proposes a new model using optimization-simulation modeling to optimize solution for the YOP, taking into account all interrelated containers terminal management activities. The proposed approach is applied to a real case study data of container terminal at Tanger Med port.

\section{EMPTy CONTAINER MANAGEMENT PROCESS}

In this paper, we assume that berth of the vessels and the assignment of the quay cranes is performed. Therefore, we start our analysis from the discharge of containers from the vessel by the quay cranes case of import, or after the pick-up of containers from the Automated Terminal Trailer (Атт) to be loaded in the vessel later on.

\section{A. Transfer Zone}

Horizontal is transport used to move containers between functional areas. Атт is used to transfer containers between quay and yard side, but they are not capable of handling containers inside those areas. Therefore, the yard cranes (YC) start later on the loading and unloading operations once the container arrives to the yard area. This requires a good synchronization between the Атт and the $\mathrm{YC}$ to avoid wasting time and creating unproductive movements. 
The simplified process for unloading:

1) ATT are waiting under the QC at the quayside

2) The QC affect the container to the first Aтт in the queue

3) Тhe Атт transfer the container to the assigned position

4) The YC already exists on the associated Block on the Yard waiting for the container or treating another one

5) The Атт arrives

6) The YC handles the container and puts it in its assigned position on the Yard (bay, block)

7) The empty Атт comes back to the dock

The simplified process for loading will be the inverse of the previous process, which means that we will start by the reaching the container from the yard side and send it by the Атт to the quayside to be loaded in the assigned vessels. As already mentioned we will focus on the empty containers, so the process is more or less the same as the loaded containers, the only difference is that the empty containers will be handled in a separated area using the Empty handler instead of the yard cranes.

\section{B. Yard Area : Yard Cranes (RTG : Rubber Tyred Gantry) and Empty Handlers (EH)}

At the port where we did our study the yard, is divided into 5 columns from 1 to 5 and 12 rows from A (Alpha) to $\mathrm{M}$ (Mike) which gives a total of 59 rectangular Blocks. These Blocks are divided into bays, each bay may contain a maximum of five containers stacked in a vertical way.

Therefore, each container position is defined by five parameters: block, row, column, bay and level. In addition to this - and for safety reasons - the Yard contains a predetermined flow direction for equipment, to manage the flow of traffic according to the management rules (Fig. 3). This Yard is segregated according to a Yard strategy. In order to facilitate the operations, the containers of the same service and same nature (empty, full, refrigerated, dangerous) are stored together.

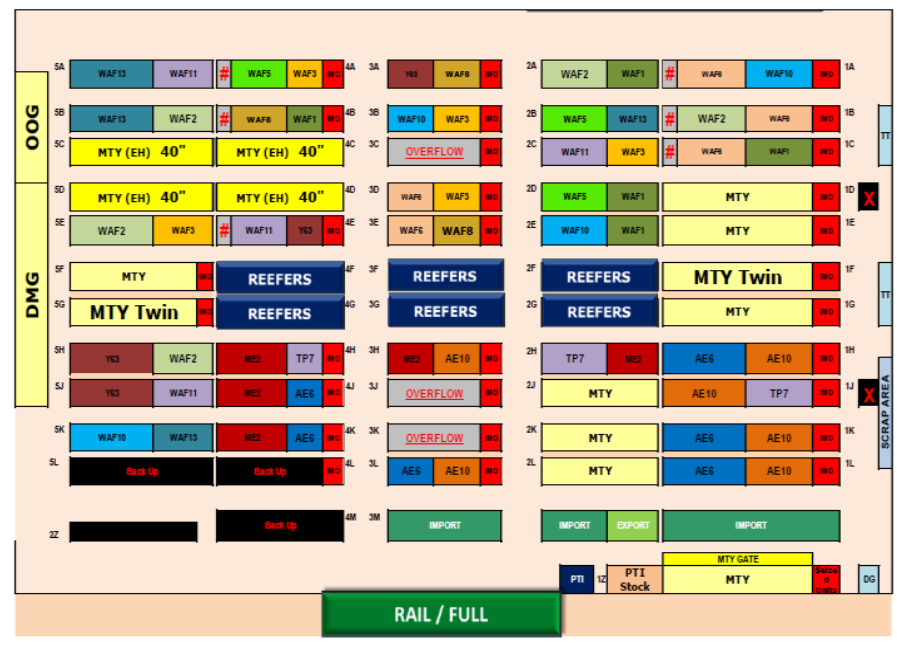

Fig. 3. Yard strategy of our port of study [12].

We creates a specific zone for the empty containers at the right of this figures where empty containers will be stored and handled by the EH. For the empty containers the maximum level per yard bay is three instead of five for full containers. The reason behind is that the form of RTG offers a considerable advantage, it can easily move on the yard above the blocks to pick or drop off containers from the yard bay.

\section{Our Case of Study}

In our simulation, we will not consider the vessel allocation process nor the assignment of equipment. Since our scope is already defined: the vessel is already in the quay. A quay crane, five Атт and an Empty Handler, handles the containers. We will focus only on the loading and unloading processes of the containers, because our aim is to show the impact of proposing doubled Атт, during these operations, on the cycle time of the QC and to the productivity of $\mathrm{EH}$.

The first empty container 40 is unloaded and transferred to the stack inside the storage area of the CT. If the EH is available, the container is transferred and the container inventory in the stack is adjusted. If not, the container is placed in the queue. The below figures shows in detail the unloading process of the empty containers. The process of loading will be the inverse of the presented process. MTY is the storage space assigned to the empty containers; we have one EH assigned to the MTY space (Fig. 4).

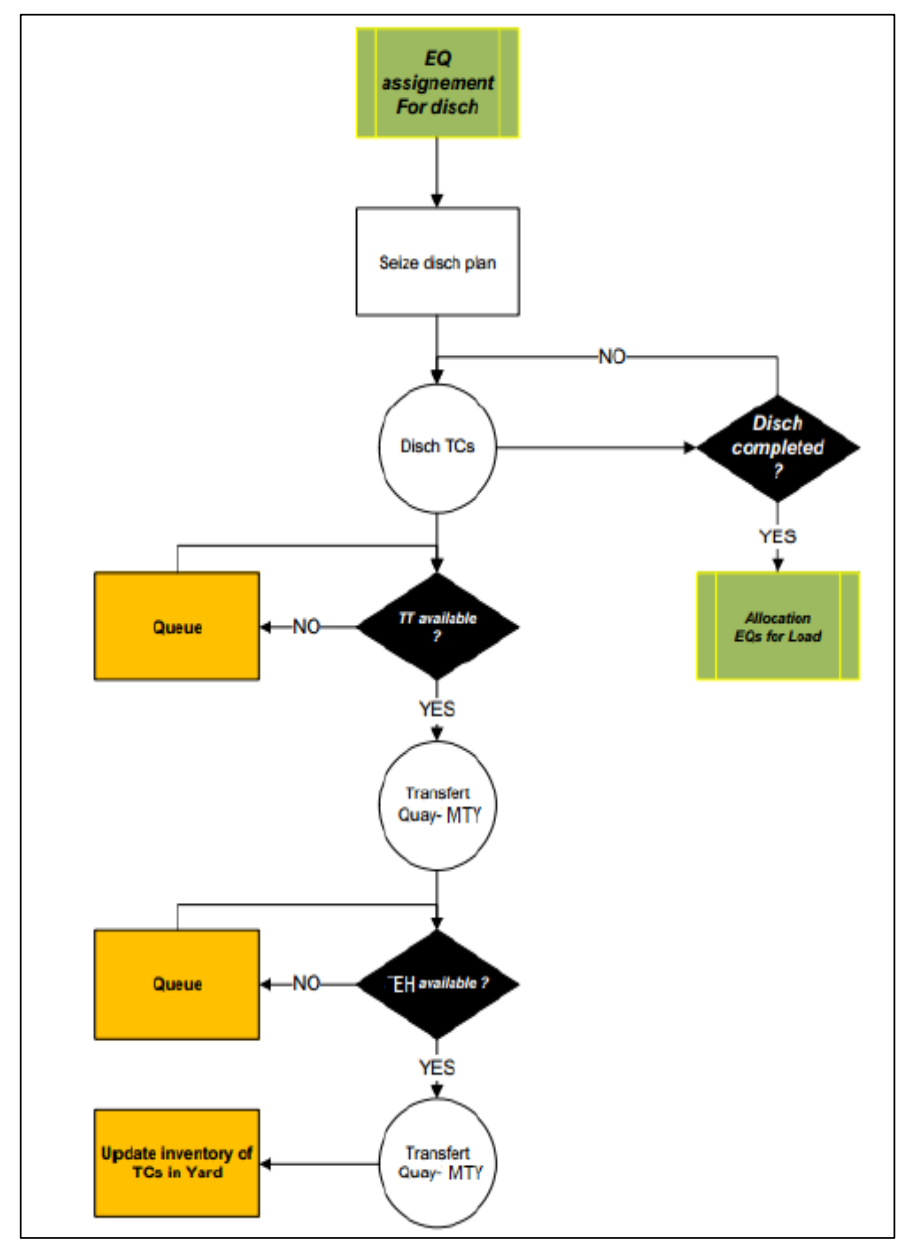

Fig. 4. Unloading process for the empty containers [13].

A deep analysis of the detailed cycle time per operation is presented below; we measure the Overall Equipment 
Effectiveness (OEE) of the Aтт (Fig. 5). GMPH is defined as a ratio between the total moves of containers and the working hours of the QC. We can see that the Aтт lost most time at the quay and yard side in queue waiting for containers, or waiting for containers to be unloaded or loaded depending on the process.

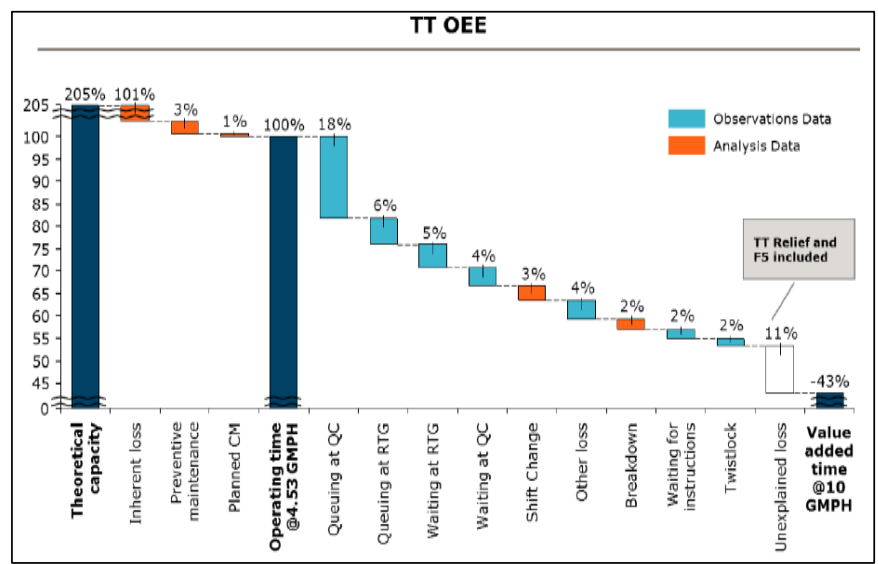

Fig. 5. Overall equipment effectiveness of ATT.

To simulate a random phenomenon such as the cycle times of a machine, statistic distribution laws must be used, the values generated by these laws must be close to the maximum values taken during the actual operation of the system. Our conclusion is that the design of the new Aтт will optimize the queue time at the quay and yard side, and will improve the volume of the transferred containers. We present in our simulation the number of moves per hour using the doubled Атт.

\section{MATHEMATICAL FORMULATION}

\section{A. Proposed Model}

We will use the model already presented by Razouk, Benadada and Boukachour (2016) [14] to build a model that is adapted to the empty containers handling and we adapt it to our case of study. In other words, the objective is to optimize the profit which corresponds to the productivity of the $\mathrm{EH}$ and minimize the cycle time of quay cranes and increase the container moves by using doubled Атт. The type $r$ of containers in our model is set to 40 feet containers; we keep the model, as is it to generalize it for other type of empty containers later on.

$$
\operatorname{Max} \sum_{k=1}^{N} \sum_{b=1}^{B} \sum_{r=1}^{R} \sum_{e=1}^{E} C_{k}^{\mathrm{b}} X_{b k}^{\mathrm{re}}
$$

The current model is a multi-objective model, which subscribe the profit maximization related to our case of study. The $\operatorname{cost} C_{k}^{\mathrm{b}}$ is a composition of the below sub-objective:

- Min QC(CT): Defines the minimization of the current cycle time of the quay crane measured.

- Min ATT(CT): Defines the minimization of the current cycle time of the ATT measured. This cycle time includes the waiting time and the queue time at the QC $\& \mathrm{EH}$. The transfer time is not taken into account as we assume that the sample and doubled ATT will have the same technical characteristics.

- Min EH(CT): Defines the minimization of the current cycle time of the EH measured.

- $\operatorname{Max} \operatorname{ATT}(\mathrm{K})$ : Defines the maximization of the number of containers transferred by the ATT.

This objective function is subject to the below constraints:

$$
\begin{aligned}
& \sum_{k=1}^{N} \sum_{r=1}^{R} \sum_{e=1}^{E} X_{b k}^{r e} \leq C_{b} ; b \in\{1, \ldots, B \\
& \sum_{b=1}^{B} \sum_{r=1}^{R} \sum_{e=1}^{E} X_{b k}^{r e}=1 ; k \in\{1, \ldots, N\} \\
& \sum_{k=1}^{N} \sum_{r=1}^{R} \sum_{e=1}^{E}\left(R_{k}-r_{b}\right) X_{b k}^{r e}=0 ; b \in\{1, \ldots, B\} \\
& \sum_{k=1}^{N} X_{b k}^{r e}=1 ; b \in\{1, ., B\}, r \in\{1, \ldots, R\}, e \in\{1, \ldots, E\} \\
& \left(t_{k}-t_{k^{\prime}}\right)\left(X_{b k}^{r e \prime}-\sum_{e=e^{\prime}+1}^{E} X_{b k^{\prime}}^{r e} \leq 0, b \in\{1, B\}, \forall r, \forall e, k \# k^{\prime}(5)\right. \\
& \sum_{k=1}^{N} X_{b k}^{r e} \geq \sum_{k^{\prime}=1}^{N} X_{b k^{\prime}}^{r e+1} ; b \in\{1, . ., B\}, r \in\{r, . ., R\}, e \in\{1, . ., E\} \\
& \sum_{k=1}^{N} \sum_{b=1}^{B} A_{b} \leq C_{A} \quad ; \forall A ; \forall T \\
& \mathrm{X}_{\mathrm{bk}}^{\mathrm{re}} \in(0,1)
\end{aligned}
$$

In the constraint (1) we define a total free positions per each yard bay, so the total number of the assigned empty containers must not exceed the numbers of free positions (this number is known at the beginning of the planning horizon). Constraint (2) ensures that each container is stored in a unique position during the planning horizon. Constraint (3) ensures that the size of the bay and the stored container is the same in each planning horizon. As we are only considering the 40 feet empty containers, this constraint will have more sense when we will includes the other type of containers. It will be used to define a clustering of the available containers, based on their size and type, and then we can allocate in the storage area a specific space to those containers (consignment strategy). Each free position in the storage space can have only one container stored at a time; this is what the constraint (4) represents. The estimated departure time is also known for each inbound and outbound container, we will consider it during the containers storage in the stacking area (5). The constraint (6) avoids empty positions between the stored containers. Constraint (7) is to ensure that the assigned containers to the Атт don't exceed the allowed capacity.

\section{B. Input Data}

Our port of study "Tanger Med Port" offers 800 meters of quay length with a depth of 18 meters for 450 meters and 16 meters for the remaining 350 meters, 40 hectares of land and it has own direct access by highway. The terminal equipment have 8 quay cranes, 26 RTG, 5 Empty Handler, and 55 trucks. The data used in this study was obtained from Tanger Med Terminal Port. The yards name, type of storage yards at Tanger Med container terminal are presented in Fig. 3. Capacity of storage yards $=1.800 .000$ (TEUs) (twenty-foot equivalent unit).

The terminal operators received the EDI file before the final arrival of the vessel, which contains the ship name \& ID, 
ship length, stowage plan, and number of containers to be unloaded \& loaded, operation type (unload/load/transshipment), size and type of containers, operation time (start/end), expected arrival time, berthing, and departure from port, destinations ports.

In this study, we use the version 14 of the ARENA simulator, which allows a smooth development of the model, and an easy access to the different modules as well as a great flexibility for external data. In addition, multitudes of statistical distributions are available to represent as much as possible the variability of the modeled phenomenon. The problems being studied are stochastic, dynamic and discrete, using the input analyzer, which use the historical data as input, the average square error and the Kolmogorov-Smirnov test as parameters. The result of this test is a value between one and zero for a parameter $\mathrm{p}$ which makes it possible to test the null hypothesis (H0), which states that two distributions laws comes from the same random distribution function, a value of $\mathrm{p}$ less than 0.05 indicates a poor correlation between the data and the distribution law. While a value greater than 0.10 shows good correspondence between the two data series and validates $\mathrm{H} 0$ [15].

\section{COMPUTATIONAL RESUlts}

As already mentioned, the result of our mathematical model for which we use Cplex as solving method, will be used as input to our simulation model.

The operational data models are based on a real case study data of container terminal at Tanger port, for one-week operation from the first until December 7, 2016. This data represents a 16 vessels arrival with containers of different sizes (20, $40 \& 45)$ and different types (full, empty, reefers) and either local or transshipped container. Implementation of the model was run with i5 CPU 2.4 GHZ, 8.0 GB RAM, Windows 10 .

The above result have been obtained using the new proposed Атт Which verifies the strength of materials constraints and which can transfer from two to four containers at the same time (Fig. 8), if we attach two trailer to the same truck. The structure of this doubled Атт is defined below.

\section{Interpretation of the Obtained Results}

In Table 1, the total number of the handled containers either for inbound or outbound or transshipment from different types and destinations expressed as global teus. The restow via yard column define the number of moves needed to redesign the storage area in order to put the containers in the right order to avoid unproductive moves. In the next column, we have the number of moves needed to unload, load and balance a specific vessel. The last two column contains the operation time per vessel either using the current model, or using the new model, which use the doubled Атт. We can see that the operation time have been optimized in the second model, which gives the opportunity to treat vessels on time and increase the number of moves related to other port operations.

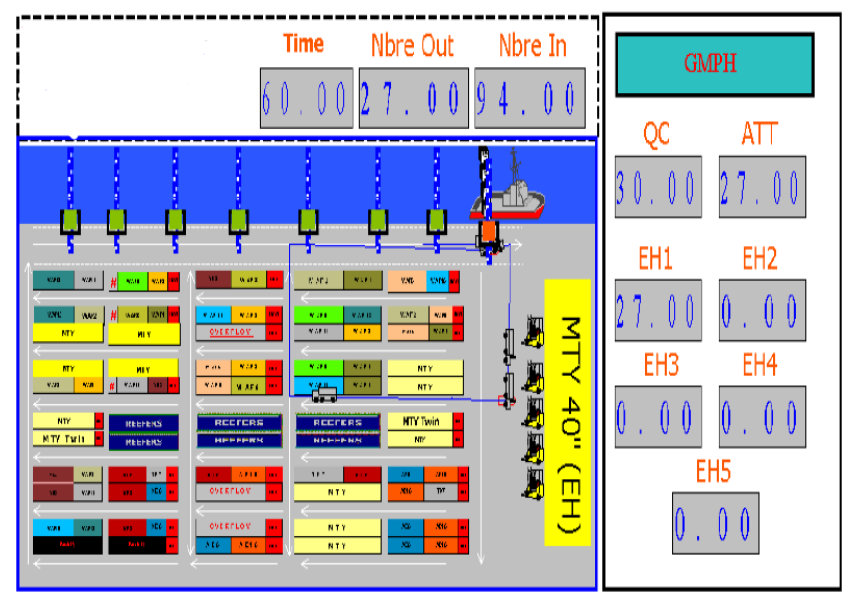

Fig. 6. Screenshot from container terminal from Arena: Actual Model.

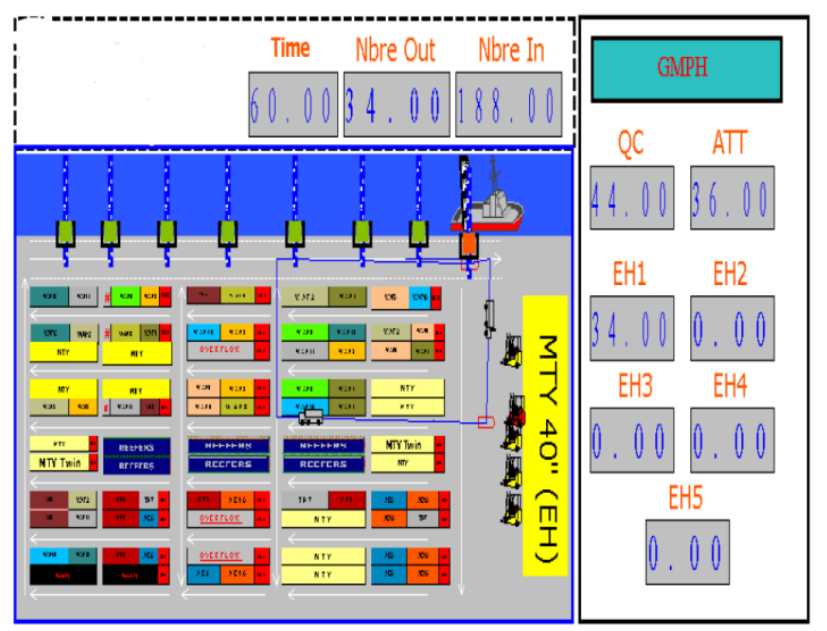

Fig. 7. Screenshot from container terminal from Arena: New Model.

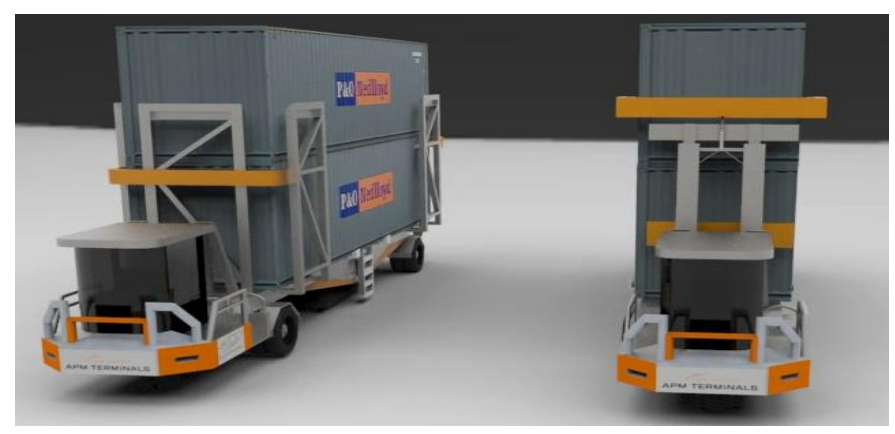

Fig. 8. Structure of the new ATT.

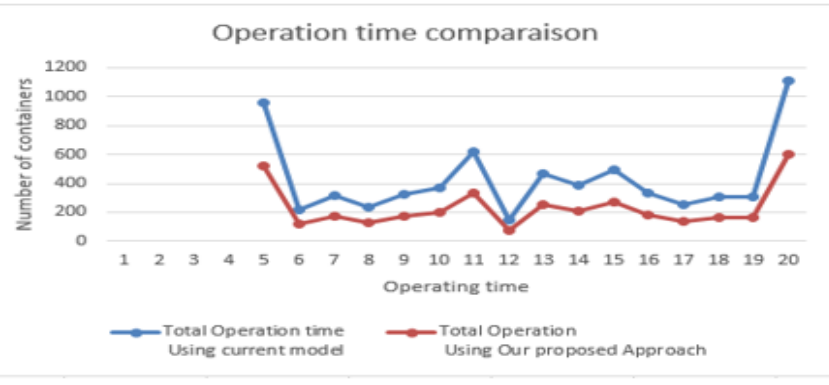

Fig. 9. Handling time comparison: old and new model. 
TABLE I. CONTAINER Terminal ACtUal OPERATION Vs OPERATION With THE PROPOSED MODEL

\begin{tabular}{|c|c|c|c|c|c|c|c|c|c|c|c|c|c|c|c|c|c|c|c|c|c|c|c|c|c|c|c|c|c|c|c|c|c|c|c|}
\hline \multirow{4}{*}{ Q } & \multirow{4}{*}{ Date } & \multirow{4}{*}{ Service } & \multicolumn{12}{|c|}{ Discharge } & \multicolumn{14}{|c|}{ Load } & \multirow{3}{*}{\multicolumn{3}{|c|}{$\begin{array}{l}\text { Restor Via } \\
\text { Yard }\end{array}$}} & \multirow{4}{*}{ Teus } & \multirow{4}{*}{$\begin{array}{l}0 \\
0 \\
\dot{2} \\
\delta \\
\overline{0} \\
8 \\
+\end{array}$} & \multirow{4}{*}{ 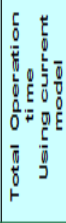 } & \multirow{4}{*}{ 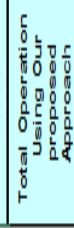 } \\
\hline & & & \multicolumn{3}{|c|}{ Emply } & \multicolumn{9}{|c|}{ Full } & & \multicolumn{5}{|c|}{ Emply } & \multicolumn{8}{|c|}{ Full } & & & & & & & \\
\hline & & & \multirow{2}{*}{$20^{\circ}$} & \multirow{2}{*}{$40^{\circ}$} & & & \multicolumn{3}{|c|}{ Local } & \multicolumn{4}{|c|}{\begin{tabular}{l|c|c}
\multicolumn{2}{l|}{ Iranshipment } \\
$\left.\right|^{\prime \prime}$ & $40^{\prime}$
\end{tabular}} & \multirow{2}{*}{\begin{tabular}{|l|}
$45^{\circ}$ \\
$D C$ \\
\end{tabular}} & & ocal & & & Shipme & & & Loca & & & & & & & & & & & & & \\
\hline & & & & & & $D C$ & & $\frac{O T}{D C} / \mathrm{R}$ & & & & $D C$ & & & & & $45^{\circ}$ & $20^{\prime}$ & $40^{\circ}$ & $45^{\circ}$ & & $7 \pi$ & & & 20 & & & $14 \mathrm{~J}$ & & 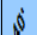 & 5 & & & & \\
\hline 1 & 1/1/21/6 11::16 & AE10 & 0 & 2 & 0 & 7 & 0 & 25 & 0 & 382 & 4 & 331 & 116 & 0 & 23 & 158 & 0 & 933 & 1742 & 0 & $\begin{array}{ll}00 \\
\end{array}$ & 0 & 1 & 5 & 596 & 237 & 16 & $\overline{0}$ & 2 & 18 & 20 & 7282 & 4615 & 960 & 518 \\
\hline 2 & 1/1/2/16 17:12 & WAF2 & 206 & 411 & 0 & 0 & 0 & 0 & 0 & 143 & 0 & 30 & 0 & 0 & 0 & 0 & 0 & 0 & 0 & 0 & 00 & 0 & 1 & & 244 & 175 & 58 & 0 & 0 & 36 & 0 & 2015 & 304 & 220 & 118 \\
\hline 3 & $2112165: 49$ & WAF5 & 345 & 279 & 0 & 0 & 0 & 0 & 0 & 0 & 0 & 0 & 0 & 0 & 0 & 0 & 0 & 0 & 0 & 0 & 00 & 1 & 0 & & 39 & 89 & 61 & 0 & 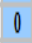 & 0 & 0 & 1244 & 814 & 315 & 170 \\
\hline 4 & 21121167:48 & $A F 3$ & 407 & 1 & 0 & 0 & 0 & 1 & 0 & 98 & 0 & 98 & 0 & 0 & 0 & 0 & 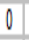 & 0 & 0 & 0 & 00 & 0 & 0 & & 49 & 21 & 5 & 0 & & 14 & 0 & 836 & 696 & 234 & $126^{\circ}$ \\
\hline 5 & 2112161010.39 & WAF7 & 265 & 238 & 0 & 0 & 0 & 0 & 0 & 69 & 0 & 1 & 2 & 0 & 0 & 0 & 0 & 0 & 0 & 0 & 01 & 0 & 0 & 0 & 225 & 123 & 18 & 0 & 0 & 0 & 0 & 1326 & 944 & 325 & 175 \\
\hline 6 & 211211621.34 & TP7 & 0 & 0 & 0 & 70 & 0 & 55 & 3 & 478 & 0 & 409 & 7 & 29 & 0 & 0 & 0 & 0 & 0 & 0 & 00 & 0 & 0 & & 1 & 25 & 1 & 0 & 4 & 0 & 2 & 1615 & 1084 & 367 & 198 \\
\hline 7 & $3 / 12161612: 39$ & NEE2 & 0 & 131 & 0 & 35 & 0 & 49 & 0 & 657 & 4 & 537 & 11 & 0 & 14 & 1 & 0 & 112 & 184 & 0 & 71 & 23 & 1 & & 182 & 154 & 199 & 0 & 0 & 6 & 0 & 3607 & 2310 & 620 & 334 \\
\hline 8 & $3 / 1211618: 00$ & WAF6 & 0 & 0 & 0 & 0 & 0 & 0 & 0 & 0 & 0 & 0 & 0 & 0 & 0 & 0 & 0 & 0 & 0 & 0 & 00 & 1 & 0 & & 171 & 30. & 4 & 0 & 0 & 0 & 0 & 799 & 485 & 142 & 76 \\
\hline$\overline{9}$ & $4 / 121 / 68: 20$ & AEG & 0 & 0 & 0 & 1 & 0 & 5 & 0 & 465 & 8 & 540 & 221 & 0 & 0 & 0 & 0 & 0 & 0 & 0 & 00 & 0 & 0 & & 241 & 102 & 0 & 0 & & 74 & 2 & 2607 & 663 & 467 & 252 \\
\hline 10 & $41221621: 11$ & WAF13 & 9 & 419 & 0 & 20 & 0 & 14 & 0 & 122 & 1 & 53 & 2 & 0 & 0 & 0 & 0 & 0 & 0 & 0 & 00 & 0 & 0 & 0 & 62 & 244 & 90 & 0 & 0 & 4 & 0 & 2072 & 1244 & 387 & 208 \\
\hline 11 & $5 / 12161613: 32$ & WAF1 & 585 & 349 & 0 & 0 & 0 & 0 & 0 & 8 & 0 & 0 & 0 & 0 & 0 & 0 & 0 & 0 & 0 & 0 & 00 & 0 & 0 & 0 & 312 & 284 & 88 & 8 & 2 & 4 & 0 & 2374 & 1641 & 498 & 268 \\
\hline 12 & $5 / 12161615.45$ & WAF9 & 73 & 141 & 0 & 0 & 0 & 1 & 0 & 231 & 0 & 35 & 10 & 0 & 0 & 18 & 9 & 218 & 370 & 6 & 00 & 0 & 0 & & 0 & 0 & 0 & 0 & 8 & 12 & 0 & 1734 & 1132 & 332 & 179 \\
\hline 13 & $5 / 1211621: 00$ & TP7 & 0 & 0 & 0 & 0 & 0 & 0 & 0 & 23 & 0 & 44 & 77 & 0 & 0 & 0 & 6 & 41 & 445 & 0 & 00 & 0 & 3 & & 4 & 30 & 148 & 0 & 2 & 34 & 0 & 1644 & 857 & 256 & 138 \\
\hline 14 & $6 / 12 / 1612: 47$ & $Y 63$ & 0 & 0 & 0 & 23 & 0 & 0 & 0 & 286 & 0 & 140 & 2 & 0 & 0 & 0 & 0 & 0 & 80 & 0 & 00 & 0 & 0 & & 200 & 299 & 9 & 19 & 0 & 0 & 0 & 1608 & 1059 & 309 & 166 \\
\hline 15 & $7 / 1211614: 49$ & WAF13 & 1 & 406 & 0 & 0 & 0 & 0 & 0 & 106 & 2 & 4 & 21 & 0 & 0 & 0 & 0 & 0 & 0 & 0 & 00 & 0 & 0 & 0 & 187 & 244 & 40 & 0 & 22 & 4 & 0 & 1759 & 1040 & 307 & 165 \\
\hline 16 & $7 / 12116192.24$ & AE10 & 0 & 0 & 0 & 3 & 0 & 13 & 0 & 283 & 2 & 226 & 205 & 0 & 8 & 8 & 0 & 1543 & 1409 & 0 & 00 & 5 & 0 & & 648 & 122 & 10 & 0 & & 384 & 88 & 7346 & 4876 & 1108 & 598 \\
\hline & & & & & & & & & & & & & & & & & & & & & & & & & & & & & & & & 39868 & 25764 & 6847 & 3689 \\
\hline
\end{tabular}

The measured GMBH from the next figures has been improved between the classical model and the new model of Aтт. This could be achieved thanks to the decrease and optimization of the operation time. The increase of the number of moves per hour indicated in the (Fig. 6) shows that the total number of inbound containers and outbound containers has been increased also (Fig. 7) using Arena software [15]. The cycle time of the $\mathrm{EH}$ and $\mathrm{QC}$ has been improved which demonstrates well the effectiveness of the proposed model, that optimizes the operation time by $54 \%$ and increase the number of moves by $48 \%$ (Fig. 9).

\section{CONCLUSION AND FUTURE WORK}

In this paper, we present a new concept of optimization and simulation of the yard optimization problem in container terminal using simulation approach for empty containers, taking into account other interrelated port terminals management activities. The collected data comes from a real case study from Tanger Med Port. Obtained results prove the effectiveness of our model in container terminal where we optimize the operation time by $54 \%$ and increase the number of moves by $48 \%$.

In the future works, we will generalize this model for other type of containers, and we will study the impact on the port terminal activities, the optimization technique will be combined to the simulation technique to provide accurate values for the resolution of the mathematical model.

\section{REFERENCES}

[1] C. Razouk, Y. Benadada and J. Boukachour " New approaches for solving the container stacking problem", IEEE Xplore: 03 November 2016, INSPEC Accession Number: 16430436. In press.
[2] Steenken, D., Voss, S., \& Stahlbock, R. (2004). Container terminal operation and operations research-a classification and literature review. OR spectrum, 26(1), 3-49.

[3] Stahlbock, R., \& Voss, S. (2008). Operations research at container terminals: A literature update. OR Spectrum, 30 (1), 1-52.

[4] Rashidi, H., \& Tsang (2013). Novel constraints satisfaction models for optimization problems. Applied Mathematical Modelling, 37(6).

[5] Chafik, R.,Benadada, Y.,Boukachour, J, "Stacking policy for solving the container stacking problem at a containers terminal ", ILS 2016 - 6th International Conference on Information Systems, Logistics and Supply Chain, KEDGE Business School -France, indexed in Scopus.

[6] Huang and Ren (2011). Research on SA-based addressing model of slot in container terminal. Applied Mechanics and Materials, 97-98, 985989.R.

[7] Jeong, Y. H., Kim, K. H., Woo, Y. J., \& Seo, B. H. (2012). A simulation study on a workload-based operation planning. Industrial Engineering \& Management Systems, 11(1), 103-113.

[8] Nishimura, E., Imai, A., Janssens, G. K., \& Papadimitriou, S. (2009). Container storage and transshipment marine terminals. Transportation Research Part E, 45, 771-786.

[9] Razouk, C.,Benadada, Y.,Boukachour, J. "Container stacking problem Mathematic model and resolution", ILS conference 2014, Castle of Breda (NL), August 24-27 2014, indexed in Scopus.

[10] Gamal A. Said, M. El-Horbaty "A Simulation Modeling Approach for Optimization of Storage Space Allocation in Container Terminal" International Journal of Computer and Information Engineering 2015.

[11] Kotachi et al., 2007. Scheduling trucks in container terminals using a genetic algorithm.Eng.Optim, 33-47.

[12] AFP study of the Tanger Med Port vol.3, Page 4-5, March, 2017.

[13] Azmi Alazzam and Harold W. Lewis, "A New Optimization Algorithm For Combinatorial Problems", (IJARAI) International Journal of Advanced Research in Artificial Intelligence, vol. 2, no.5, 2013.

[14] Razouk, C.,Benadada, Y.,Boukachour J, "Adapted Bin-Packing algorithm for the yard optimization problem", Chapters springer book, Bioinspired heuristic optimization. Unpublished

[15] Arena : http://www.arenasimulation.com/Arena_Home.aspx 